\title{
¿Cómo ha ido evolucionando la revista?
}

stoy de verdad muy contenta del apoyo y respuesta que hemos tenido frente al llamado de generar una revista chilena de anestesiología ágil, atractiva para los lectores y muy vigente en las redes sociales.

Vamos cumpliendo las metas que nos planteamos y se va generando este círculo virtuoso, mientras mejores e interesantes sean nuestros artículos, tendremos más lectores e investigadores interesados en publicar.

Hemos recibido trabajos originales, casos clínicos, temas de reflexión de toda iberoamérica, tal como lo demuestra el tweepsmap de @chileanestesia.

En este número tenemos dos artículos muy destacables.

El primero es un artículo de reflexión, escrito por el Dr. Alejandro Recart, sobre el cambio que ha ido presentando nuestra especialidad. ¿Será que la medicina perioperatoria es nuestro futuro rol? ¿Tendremos que tener un papel más activo en cuanto a la definición de las prestaciones?
Los invito a leerlo y a través de este mismo medio publicar sus opiniones en la sección de cartas al editor, sería interesante que discutamos estos temas y este es uno de los medios para hacerlo.

Queda entonces extendida la invitación.

El segundo artículo, del Dr. Delmau, es una profunda reflexión sobre la fisiología cardiovascular, al final del día, la gran pregunta ¿qué es ser respondedor a volumen? Queda dando vuelta en nuestras cabezas. $\mathrm{Y}$ es motivo de la portada de nuestro número actual.

Así, entonces, partimos con nuestro tercer número del año, año que ha resultado ser muy productivo y esperamos que siga aumentando aún más.

¡Gracias a todos los que nos han enviado sus experiencias y gracias a los que están escribiendo sus experiencias para ser publicadas en esta revista!

\#publique en su revista chilena de anestesia

\section{Dra. María Carolina Cabrera Schulmeyer} Editora Jefe Revista Chilena de Anestesia

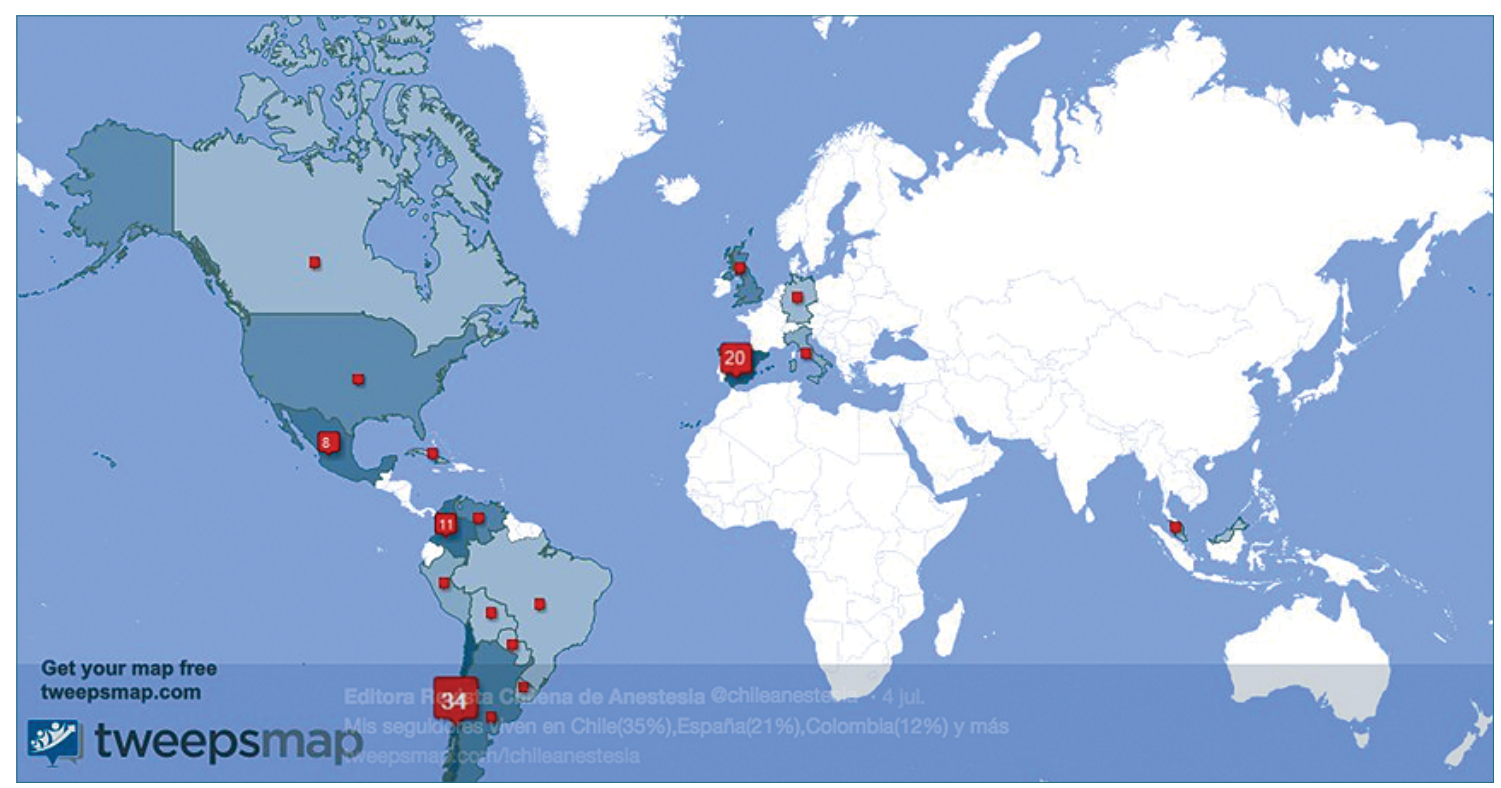

